\title{
Are hypotheses necessary in ecology and evolution?
}

\author{
Matthew Betts ${ }^{1}$, Adam Hadley ${ }^{1}$, David Frey ${ }^{1}$, Sarah Frey ${ }^{1}$, Dustin Gannon ${ }^{1}$, Scott Harris ${ }^{1}$, \\ Hankyu Kim ${ }^{1}$, Kara Leimberger ${ }^{1}$, Katy Moriarty ${ }^{1}$, Joseph Northrup ${ }^{2}$, Ben Phalan ${ }^{3}$, Josee \\ Rousseau $^{1}$, Thomas Stokely ${ }^{1}$, Jonathon J. Valente ${ }^{1}$, and Diego Zarrate-Charry ${ }^{1}$ \\ ${ }^{1}$ Oregon State University \\ ${ }^{2}$ Trent University \\ ${ }^{3}$ University of Cambridge
}

January 18, 2021

\begin{abstract}
Research hypotheses have been a cornerstone of science since before Galileo. Many have argued that inclusion of multiple hypotheses (1) encourage discovery of mechanisms, and (2) reduce bias - both features that should increase transferability and reproducibility. However, we are entering a new era of big data and highly predictive models where some argue the hypothesis is outmoded. Indeed, using a detailed literature analysis, we found prevalence of hypotheses in eco-evo research is very low (6.7-26\%) and static from 1990-2015, a pattern mirrored in an extensive literature search (N=302,558 articles). Our literature review also indicates that neither grant success or citation rates were related to the inclusion of hypotheses, which may provide disincentive for hypothesis formulation. Here we confront common justifications for avoiding hypotheses and present new arguments based on benefits to the individual. Although hypotheses are not always necessary, we expect their continued and increased use will help our fields move toward greater understanding, reproducibility, prediction, and effective conservation of nature.
\end{abstract}

\section{Hosted file}

Hypothesis_paper_Ecol and Evol_final.pdf available at https://authorea.com/users/390230/ articles/504626-are-hypotheses-necessary-in-ecology-and-evolution 